\title{
Perception, Environmental Degradation and Family Size Preference: a Context of Developing Countries
}

\author{
Shah Md. Atiqul Haq (Corresponding author) \\ Human Ecology Department, Vrije Universiteit Brussel \\ GF MEKO, Laarbeeklaan 103, 1090, Brussels, Belgium \\ Tel: 32-04883-84927 E-mail: shahatiq1@yahoo.com
}

Tom Vanwing

Vrije Universiteit Brussel, PE AGOG

Pleinlaan 2, 1050, Brussels, Belgium

Tel: 32-02629-2624 E-mail: tvwing@vub.ac.be

Luc Hens

Human Ecology Department, Vrije Universiteit Brussel

GF MEKO, Laarbeeklaan 103, 1090, Brussels, Belgium

Tel: 32-02477-4947 E-mail: human.ecology@vub.ac.be

\begin{abstract}
This paper explores how people perceive about family size and environmental degradation. Many studies explain people perception to family size or environmental degradation independently. Considering both of the concepts as interrelated, how people consider the relation between family size and environmental degradation, and how their perception subsequently influence on contraceptive use in developing countries. People who think their immediate environment such as land productivity, soil fertility, water level and biodiversity is declining are more concerned about their family size and contraceptive use than who do not think that their environment is declining. Children in poor area or forest area are involved with fuel wood and water collection. Parents especially women perceive additional child as helping hand in domestic work or fuel wood and water collection. In reality socioeconomic development particularly women education, participation to reproductive decision and access to contraception, and improvement of environmental qualities such as proper sanitation, drinking water, and environmental awareness are important to change people perception to larger family size. As a result people will start thinking that environmental degradation is the result of over access to natural resources.
\end{abstract}

Keywords: Contraceptive use, Environmental degradation, Family size preference, Perception, Socio-economic factors

\section{Introduction}

Population growth and environmental deterioration has become a new important focus in the public and ecological research studies (Dunlap et al. 1993) as a global phenomenon in developed and developing countries. Relationship between environmental degradation and choice of family size is complex and many claim that poor environmental conditions produce lower demand for children (Axinn and Barber 2005) and others say that fertility behaviour and perception of family size may have impacts on environmental conditions (Rosero-Bixby and Palloni 1998; Axinn and Ghimire 2002; Foster and Rosenzweig 2003). And the people, who are experiencing high fertility, may choose to revise their fertility behaviour and perception (Ghimire and Mohai 2005). But in developing countries cultural values support high fertility and oppose to use of contraceptive by family members, and make worries about health risks or side effects of contraception (Carr and Khan 2004). If people perceive large number of family size and culture influence people not to use contraception, then the population growth will continue, add environmental burden and undermine the prospects for socioeconomic developments very significantly (Wilson 2002).

And high population growth will deplete natural resources and impair the capacity of life supporting ecosystems (Brown 2004; Wilson 2002; World Resources Institute 1998). So population growth is the reason why human have changed ecosystems more rapidly and it has been changed extremely over the past 50 years than during any other period. Because, in that period, large number of people than any other period creates more demands for food, fresh water, timber, fibre and fuel (Speidel et al. 2007). And 60\% of ecosystem services, the benefits people obtain from ecosystems are being degraded or used unsustainably (Millennium Ecosystem Assessment 2005).

\section{Methodology}

The reasons behind the relation between family size and environmental degradation might not be understood simply through the study of particular disciplinary approaches such as sociological or demographic or 
environmental. So there is needed to incorporate and integrate knowledge based on the multidisciplinary approaches. Furthermore the paper is part of an empirical studies based on the literature review, field work and so on. Basically the paper is developed by secondary sources of information. In the paper, search engine "Google Scholar" and VUB university database were used through the link-www.vub.ac.be to review relevant literatures. Gathered important information on the perception of family size and environmental degradation were organized by searching relevant published articles on the internet. Title of the paper and most important keywords -contraceptive use, environmental degradation, and family size, perception of family size, perception of environmental degradation, and environmental perception were employed to find published articles. The findings of this article are currently used in the further phases of the research.

\section{Review of Literature}

Environmental degradation is an important issue globally and locally. In many developing countries, high population growth is a great problem to environment and development. Many studies claim that population growth is a significant cause of environmental degradation. But people's perception to environmental degradation and choice of family size is simultaneously important to analyze in considering the concepts as interrelated since people perception to environmental degradation may influence to use contraception and family size. Therefore many literatures and studies were searched to find relevant literatures and information regarding the developing countries.

\subsection{Perception, Environment and Contraceptive Use}

In the study of Western Chitwan Vally in South-Central part of Nepal, Ghimire and Mohai (2005) find relation between individual's perception about immediate environment and fertility behaviour. People, who perceive their immediate environment is declining will use contraceptive than those who do not perceive environment as declining. Most of people who think the crop production, ground water table and water quality have decreased compared to previous years have ever used contraceptive methods (Ghimire and Mohai 2005).

However perceiving things such as agricultural productivity, ground water table and water quality declining have a positive effect on the rate of contraceptive use. Those who think agricultural productivity has decreased used contraceptives at rates $72 \%$ higher than those who think agricultural productivity has remained the same or increased in the past three years (Ghimire and Mohai 2005).

Gender has a significant effect on contraceptive use. $31 \%$ women are less likely to use contraceptives compared to men in Chitwan Vally in Nepal (Ghimire and Mohai 2005). And educational experiences and number of children has positive effects on the contraceptive use and those who are educated are more likely to use contraceptives (Axinn and Barber 2001; Axinn and Yabiku 2001). People who have more children are more likely to use contraceptives than those who have fewer children (Ghimire and Mohai 2005).

\subsection{Perception, Environment and Family Size Preference}

Biddlecom, Axinn and Barber (2005) also shows in their study of Western Chitwan Vally in South-Central part of Nepal that environmental degradation is positively associated with large family size preference. Women's and men's desired family size increases if the time to collect fuel wood and fodder increases over time. Households that depend on forest products such as collection of wood and fodder from public lands have a strong positive effect on family size preference. Dependence on public land for natural resources and resource scarcity has a positive effect on fertility preferences and behaviours (Biddlecom et al. 2005). In Nepal, evidences show that women are more responsible for fuel wood collection activities and spend more time engaged in such activities than men (Cooke 1998).

Social demography in Latin America produces some useful concepts which attempt to synthesize the varying roles played by individual perceptions to shape population structure and responses to changing environmental conditions (Izazola et al. 1998). Concepts such as social reproduction, household survival strategies (Gregory 1978) and life course (Tuiràn 1993) have influence on the ways in which individual perceptions and intentions interact with household characteristics (size, age structure and income level), community and societal level factors (e.g. economic opportunities and socioeconomic class). The importance of considering the perceptions of the physical environment held by different social groups has also recently been emphasized in relation to understanding population responses to deforestation in southern Mexico (Arizpe et al. 1993). The study in Mexico shows that the middle-income group reflected a wide notion of the environment which encompassed physical conditions such as air pollution as well as less tangible factors relating to the overall "quality of life" (e.g. traffic, noise, distance to place of work, aggressiveness of city residents). Among the lower-income households, environmental perceptions focused more narrowly on those aspects most linked with daily existence such as land quality (Izazola et al. 1998).

People's perceptions to environmental degradation and family size are important to understand for several reasons. Firstly, perceptions of environmental degradation serve as useful indicators of objective environmental degradation when objective data are not available. Secondly, perceptions influence grassroots participation in programs and policies aimed at improving environmental conditions and lower fertility rate in developing countries (Daniere and Takahashi 1999). Thirdly, perceptions of environmental degradation and family size have 
significant influence on individual's environmental and fertility behaviours. Less empirical research in poor countries focuses on environmental degradation at more local levels such as communities or neighbourhoods in which individuals spend most of their daily life. So dimensions of environmental quality such as availability of common grazing and forest land, degree of land productivity, biodiversity and quality of water are most likely to affect the daily lives of any local peoples and subsequently fertility behaviour in developing countries.

\subsection{Education, Environment and Fertility Behaviour}

Education has a great influence on the family size preference and understanding of environmental conditions. As women's educational level goes up, they are likely to have more access to birth control (Dissanayake 1996; Castro-Martín 1995). Since educational process makes more information available to women and may expose them to increase understanding about the family size, environmental degradation, their children's health, further educational opportunities and contraceptive use. Usually educated women may prefer to get married educated men who will be more positive to contraceptive use and lower family size.

When women's educational level will rise, their desire for children typically will decrease. And the result is that the typical number of children born per woman will go down (Barkat-e-Khuda and Hossain 1996) and there will be fewer impacts on environment. As a result society's perceptions about the appropriateness of education for women go up. And that will further lead to perceive in individual level to decrease family size (Colfer and Byron 2001). Women's educational level strengthens their desire for birth control and women's involvement in productive work, whether paid or subsistence labour, affects their involvement in reproductive behaviour (Sanday 1974). A study on 33 countries shows that most women who worked for cash for a non-family enterprise have lower fertility (Muhuri et al. 1994).

In another study of Sunyani Municipality (Ghana) J.L Arthur (2006) shows that the level of education of siblings is influenced by the number of children in the family. Higher family sizes have resulted in lower educational attainment of children in such families whilst the opposite holds for families of smaller sizes. Also the study shows that many households are influenced in the choice of their family sizes by factors including culture, incomes and residence, and households with smaller family sizes enjoy better social and economic life in compare to their counterparts with relatively large family sizes (Arthur 2006).

\subsection{Culture, Environment and Fertility Behaviour}

In developing countries, culture highly influences on family size preference. Furthermore choice of family size is a culture-dependent issue. The awareness and access to contraceptive use depend upon technological development, desired number of family size and socioeconomic factors. Socio-economic factors influence the perceptions of advantages and disadvantages of larger family size and greater fertility. But the reduction of desired family size depends upon crucial developmental tasks such as increase of life expectancy, improvement of the environment (drinking water, sanitation, housing, etc.), education of women, diversion of children away from life-support tasks (fuel wood, fodder and water collection) and employment to schooling (Batliwala and Reddy 1993). The Nobel laureate economist Amartya Sen has noted that in recent times Bangladesh experienced an unusual sharp reduction in fertility rates because of the expansion of family planning opportunities, greater involvement of women in economic activities, much public discussion on the need to change the prevailing patterns of gender disparity and the greater social and economic role of women in Bangladesh (Sen 2000). NGOs are working on the grassroots level to aware people, provide information and facilitate access to family planning and contraceptive use but these services are not adequately exist to indigenous people living in forest area in Bangladesh.

Colfer and Byron (2001) have identified five issues such as availability of birth control, use of birth control; desire to bear children, typical number of children born per woman, and time used for reproductive activity that people perceive are closely related to decisions about childbearing. Factors affecting individual's decision to additional children are children's useful functions to serve as insurance and companionship in old age, workers on the farm, helpers around the house in many parts of the world especially in developing countries.(Barkat-e-Khuda and Hossain 1996).

Freedman (1963) says that normative values have a key role in explaining differentials in fertility. The related factors such as cultural and traditional beliefs (Arthur 2006), female autonomy, and socio-economic status are assumed to affect fertility. Ideal family size is an indicator of fertility preference. A study on Khasi and Karbi indigenous communities in India shows a strong preference for sons among the Karbis and a strong preference for daughters among the Khasis (Saikia et al. 2001). And the study finds that when the ideal family size is an even number 2 or 4, a majority of the women in both communities want an equal numbers of sons and daughters. But when the ideal family size is an odd number, the Karbi women prefer to have a larger number of sons than daughters and the Khasi women prefer to have a larger number of daughters than sons in their family (Saikia et al. 2001).

Early marriage is a social norm throughout much of South Asia, and it almost always leads to early childbearing (Adhikari, 2003). Nearly three out of five (59\%) currently married 15-19 year-old Bangladeshi girls had already their first child (National Institute of Population Research and Training (NIPORT 2005). Evidence from 
Demographic and Health Surveys (DHS) between 1989 and 2000 showed an increasing age at first marriage among females. The proportion of women ages 20-24 years first married by age 18 fell from $73 \%$ in 1989 to $65.3 \%$ in 2000 . The 2004 survey, however, suggests a stagnation or reversal in this trend, with $68.4 \%$ of women ages 20-24 married by age 18 (National Institute of Population Research and Training (NIPORT 2005).

\subsection{Child Labour, Environment and Fertility Behaviour}

Dasgupta (1995a, 1995b, 1998) and other researchers have suggested that there may be a cyclical (or feedback) relationship between population growth, environmental degradation and poverty particularly in the poorest rural communities of developing countries. The model is based on the observation that families in poor countries depend on child labour as a means of exploiting the local environment and it has long been understood that child labour is an essential part of family life in poor countries (Dasgupta 1995a, 1995b, 1998). For example, Cain (1977) and, Loughran and Pritchett (1997) describe a variety of household uses child labour in rural Bangladesh and Nepal respectively. Dasgupta (1995a), and Dasgupta and Maler (1995) also find that children are often required to spend several hours each day fetching fresh water or gathering fuel wood. As these local natural resources become more scarce and distant due to over-exploitation, having more children could be seen to provide more helping hands during difficult times. If every family chooses to have more children, then these individual choices would lead to even more pressure on the local environment which would in turn lead to a lower standard of living for every family and an even greater impact on local environment.

There are empirical studies describing the resource gathering role for child labour in poor countries and the potential linkages between population, poverty and the local environment. Nerlove $(1991,1993)$ have pursued an understanding of their interaction in a model which is called two period overlapping generations model. According to the model, individuals spend the first period of their lives as children supporting their parents by exploiting local environmental resources and spend the second period living from the support of their own children. Then, depending on parent's perceptions of the relationship between family income and the productivity of children in exploiting the environment, the dynamics of the model can result in simultaneous population growth and environmental decline.

\subsection{Wealth Flow, Environment and Fertility Behaviour}

In an analysis based on the observation in the poorest countries, Gorazd Ruseki and John Quinn (2007) show that, in the absence of well-defined property rights to local natural resources, parents may have a unilateral incentive to have more children if it is perceived that doing so enables their families to capture a greater share of the net benefits from production on the commons. However it was also shown that this form of rivalry in the commons can result in too many children in each family, over-exploitation of the local environment and diminished net benefit from production on the commons according to each family (Gorazd Ruseki and John Quinn 2007).

One popular theory to explain the existence of sustained high fertility in the face of declining environmental resources is the vicious circle model (VCM) (O'Neill et al. 2001, Lutz and Scherbov 1999). The VCMs build on intergenerational wealth flows theory which holds that high fertility in traditional societies is beneficial to older generations due to the net flow of wealth from children to parents (Caldwell 1982). It should be noted that VCMs have been criticized as being oversimplified and as 'blaming the victim' rather than examining deeper political, economic and institutional imbalances that set the context for environmental degradation (Gray and Moseley 2005; Krings 2002; Forsyth et al. 1998).

Moreover Filmer and Pritchett (2002) find qualified support for the vicious circle hypothesis using detailed data from Pakistan on child time use, firewood collection activities and recent fertility. They find that collection activities do absorb a substantial part of household resources and children's tasks are often devoted to collection activities. In comparison to the time spent by other household members, child time is a significant but not dominant. The presence of older children in the household was found to reduce the time that women devoted to household tasks. From exploratory multivariate regressions, they conclude that the results "support the notion that there is a stage in the relationship between environmental degradation, fertility and land ownership rights in which children are in relatively high demand".

Fuel wood and water are necessary for everyday life in indigenous communities living in forest area. In rural areas these tend to be collected from ungoverned commons such as forests and rivers. And resource's gatherings are often left to women and children. Dasgupta (2000) hypothesizes that as these resources become scarce each additional child provides a marginal benefit through his or her labour. This suggests that resource dependency will result in higher fertility. There is empirical evidence supporting this hypothesis from Pakistan, Nepal, and South Africa (Biddlecom et al. 2005; Aggarwal 1997; Filmer and Pritchett 2002). A carefully designed study in the Western Chitwan Valley of Nepal find that three measures of environmental constraint - the time to collect fodder, the increase in time required to collect fodder and household's dependence on public lands for fodder are significantly and positively correlated with desired family size (Biddlecom et al. 2003).

In a study of Guatemala's Petén, an agricultural frontier, Sutherland et al. (2004) using number of living children as the dependent variable (family size) and controlling for maternal age, education and living standards, they find that neither farm size nor tenure security has significant effects on family size. Those perceiving land to be 
available for their children has significantly fewer children than those who perceive land to be scarce and children may be seen as an economic safety net for those who perceive resources to be scarce.

\section{Conclusion}

People perception to environment and family size is very important to use contraception. People who perceive their immediate environment is declining will use contraceptive than those who do not perceive environment as declining. If people perceive that their environment is degrading for excessive access into the natural resources, they may adopt to use contraception and reduce family size. Parent's education also influence on children to be aware about contraception and environmental degradation, and parents can explain significance of natural resources to their children and the negative effects of additional children on their livelihood and environment. People who are concerned with the deteriorating environment do make certain adjustments in their life style and behaviour. The adjustments people make in their tastes, preferences and ultimately in their behaviour, have profound implications for the delicate relationships that human beings have with their environment (Ghimire and Mohai, 2005).

Population growth always is not a cause to environmental degradation. Inversely environmental degradation has also an effect on the choice of a family size. For instance, people desire to family size also increase when the fuel wood, fodder and water collection time increase. Actually awareness to contraception or lowering family size depends upon the socio-economic factors, desired number of family size, educational level and technological development of a community. And perception to advantages and disadvantages of family size depend upon the socio-economic factors such as improvement of environment, educating women and diverting children from fuel wood and water collection to school by developing a positive perception about future benefits of educating children and environment. Because educational experiences have a positive effect on the contraceptive use and those who are educated and concerned about environmental degradation, are more likely to use contraceptives (Axinn and Barber 2001; Axinn and Yabiku 2001). But educational facilities, access to contraceptive use and health facilities are very important to reduce family size through developing perception about the effects of additional children on environment. And the improvement of socio-economic factors especially educational facilities, employment opportunities and consciousness building by mass media about the negative impacts of large family size on environment are very important to ensure in developing countries.

Population and environment has been a prevailing issue among the researchers, public and policy makers regarding impact of population growth on environmental degradation especially in developing countries. The negative blow of environmental degradation on humanity has resulted in a rise in public environmental concern what has become a worldwide discussion and in ecological research. Furthermore the complex connection between environmental degradation and family size can be understood through using multidisciplinary approaches for in-depth understanding and developing of EAI (Environmental Awareness Index) at local level which will indicate people perception to environment and family size preference living in rural area or forest areas in developing countries. So the addressing of multidisciplinary research about environment could be more influential to enhance understanding of present environmental and fertility behaviour, and suggest concrete policy research in developing countries.

\section{References}

Adhikari, R.K. (2003). Early marriage and childbearing: Risks and consequences. In: S. Bott et al., Editors, Towards adulthood: Exploring the sexual and reproductive health of adolescents in South Asia, World Health Organization, Geneva (2003), pp. 62-66.

Agarwal, B. (1997). Gender, environment, and poverty interlinks: Regional variations and temporal shifts in rural India, 1971-91. World Development, 25(1), 23-52.

Arizpe, L., F. Paz and M. Velázquez. (1993). Cultura y cambio global: percepciones sociales sobre la deforestación en la selva lacandona, Centro Regional de Investigaciones Multidisciplinarias, UNAM and Grupo Editorial Miguel Angel Porrúa S.A., Mexico.

Arthur, J.L. (2006). Family Size and Quality of Life Nexus- Case of the Sunyani Municipality, Ghana. Presented in the Fifth African Population Conference, Arusha, Tanzania: 10-14 December 2007.

Axinn, W. G., and Barber, J.S. (2005). Environmental Effects on Family Size Preferences and Subsequent Reproductive Behavior in Nepal, Population and Environment, 26(3):583-621.

Axinn, W. G., and Ghimire, D. J. (2002). Population and environment:The impact of fertility on landuse in an agricultural society. Paper presented at the Annual Meeting of the Population Association of America, May 9-11, Atlanta, GA.

Axinn, W. G., and Barber, J.S. (2001). Mass education and fertility transition. American Sociological Reveiw, 66(4), 481-505.

Axinn, W. G., and Yabiko, S. (2001). Social change, the social organization of families, and fertility limitation. American Journal of Sociology, 106, 1219-1261. 
Barkat-e-Khuda and M. Hossain. (1996). Fertility decline in Bangladesh: An investigation of the major factors. Maternal and Child Health-Family Planning (MCH-FP) Extension Project (Rural) Working Paper No. 111; ICDDR, B (The International Centre for Diarrhoeal Disease Research, Bangladesh) Working Paper No. 48: 28.

Batliwala, S and Reddy, A. K.N. (1993). Energy Consumption and Population. This paper has been prepared for the Population Summit of the World's Scientific Academies, New Delhi, October 24-27, 1993.

Biddlecom A.E., W. Axinn and J.S. Barber. (2005). Environmental Effects on Family Size Preferences and Subsequent Reproductive Behavior in Nepal, Population and Environment, 26(3):583-621.

Biddlecom, Ann E., Axinn, William G. Barber, and Jennifer S. (2003). Neighborhood Social Change and Perceptions of Environmental Degradation. Population and Environment, Vol. 25(2). 77-108.

Brown, L.R. (2004). Outgoing the earth: The food security challenge in an age of falling water tables and rising temperatures. W.W. Norton\& Company, Inc.

Caldwell, J.C. (1982). Theory of Fertility Decline. London: Academic Press.

Cain, M. (1977). The economic activities of children in a village in Bangladesh, Population and Development Review, 3, 3:201-7.

Carr, D., and Khan, M. (2004). The unfinished agenda: meeting the need for family planning in less developed countries. Washington, DC: Population Reference Bureau.

Castro-Martín, T. (1995). Women's education and fertility: Results from 26 demographic and health surveys. Studies in Family Planning. 26(4):187-202.

Colfer, C.J.P. and Y. Byron. (2001). People Managing Forests: The Links between Human Wellbeing and Sustainability.Washington. DC/Bogor, Indonesia: Resources for the Future/Center for International Forestry Research.

Cooke, P.A. (1998). Intrahousehold labour allocation responses to environmental goods scarcity:A case study from the hills of Nepal. Economic Development and Cultural Change, 46(4), 807-830.

Daniere, A. G., and Takahashi, L. M. (1999). Environmental behavior in Bangkok, Thailand: A portrait of attitudes, values, and behaviors. Economic Development and Cultural Change, 47(3), 525-557.

Dasgupta, P. (1995a). Population, poverty, and the local environment, Scientific American 272, 2:40-6

Dasgupta, P. (1995b). The population problem: theory and evidence, Journal of Economic Literature, 33, 4:1879-1902

Dasgupta, P. (1998). The economics of poverty in poor countries, Scandinavian Journal of Economics, 100, 1:41-68

Dasgupta, P. and K.-G. Mäler. (1995). Poverty, institutions, and the environmental resource-base, in Handbook of Development Economics, Vol. IIIA (J. Behrman and T.N. Srinivasan, eds.), Elsevier, Amsterdam.

Dissanayake, L. (1996). Relative impact of 'starting, spacing and stopping fertility behaviour' in Sri Lanka. The Journal of Family Welfare 42(3): 1-7.

Dunlap,R.E., Gallup, G.H.Jr., and Gallup, A.M. (1993). Health of the Planet. Princeton, NJ: George Gallup International Institute.

Filmer, D., and L.H. Pritchett. (2002). Environmental degradation and the demand for children: searching for the vicious circle in Pakistan. Environment and Development Economics, 7 (2002): 123-146.

Forsyth, T., M. Leach, and I. Scoones. (1998). Poverty and Environment: Priorities for Research and Policy. Sussex, UK: Institute for Development Studies.

Freedman, R. (1963). Norms for Family Size in Underdeveloped Areas, Proceedings of the Royal Statistical Society, 159, 220-234.

Gray, L.C., and W.G. Moseley. (2005). A geographical perspective on poverty-environment interactions. The Geographical Journal, Vol. 171, No. 1, March 2005, pp. 9-23.

Ghimire,D.J., and Mohai, P. (2005). Environmentalism and Contraceptive Use: How people in less developed settings approach environmental issues. Population and Environment. Vol. 27, (1) 29-61.

Gregory, D. (1978). Ideology, Science and Human Geography, Hutchinson, London.

Izazola, H., Martinez, C., and Marquette, C. (1998). Environmental perceptions, social class and demographic change in Mexico City: a comparative approach. Environment and Urbanization. Vol.10(1).107-118.

Krings, T. (2002). A critical review of the Sahel Syndrome concept from the viewpoint of Political Ecology. Geographische Zeitschrift, 90(3-4): 129-141.

Loughran, D. and Pritchett, L. (1997). Environmental Scarcity, Resource Collection, and the Demand for Children in Nepal, World Bank, Washington, DC. 
Lutz, W., and S. Scherbov. (1999). Quantifying Vicious Circle Dynamics: The PEDA Model for Population, Environment, Development and Agriculture in African Countries. IIASA Interim Report IR-99-049, Laxenburg, Austria: International Institute for Applied Systems Analysis.

Millennium Ecosystem Assessment. (2005). Ecosystem and human well-being: Synthesis. Washington, DC: Island Press.

Muhuri, P. K., A. K. Blanc, and S. O. Rutstein. (1994). Socioeconomic differentials in fertility. Demographic and Health Surveys Comparative Studies. Calverton, Maryland, Macro International: 79.

Nerlove, M. (1991). Population and the environment: a parable of firewood and other tales, American Journal of Agricultural Economics, 73, 5:1334-1347.

Nerlove, M. (1993). Procreation, fishing, and hunting: renewable resources and dynamic planar s National Research Council. (1993). Population and land use in developing countries. Washington, DC: National Academy Press ystems, American Journal of Agricultural Economics, 75, 1:59-71.

National Institute Population Research and Training NIPORT. (2005). National Institute of Population Research and Training (NIPORT) et al. (2005). Bangladesh demographic and health survey 2004. Dhaka \& Calverton: NIPORT, MA, and ORC Macro.

O'Neill, B.C.; MacKellar, F. L.; Lutz, W. (2001). Population and climate Change. Cambridge, UK:Cambridge University Press.

Rosero-Bixby, L., and Palloni, A. (1998). Population and deforestation in Costa Rica. Population and Environment, 20(2), 149-178.

Ruseki,G., and Quinn. (2007). Human Fertility Decisions and Common Property Resources: A Dynamic Analysis. NATURAL RESOURCE MODELING. Volume 20, Number 3, Fall 2007.

Saikia,U.S., Steele,R., and Dasvarma, G. (2001). Culture, Religion and Reproductive Behaviour in Two Indigenous Communities of Northeastern India: A Discussion of Some Preliminary Findings. http://www.iussp.org/Brazil2001/s50/S50_02_Saikia.pdf (20 April, 2009).

Sanday, P. (1974). Female status in the public domain. In Woman, Culture and Society edited by M. Z. Rosaldo and L. Lamphere. Stanford, California: Stanford University Press.

Sen., Amartya. (2000). 'The means and means of sustainability', key note address at an international conference on "Transition on sustainability" May 2000.

Speidel, J.J., Weiss, D., Ethelston.S., and Gilbert, S. (2007). Family planning and reproductive health: the link to environmental preservation. Population Environment. 28:247-258.

Sutherland, E.G., D.L. Carr, and S.L. Curtis. (2004). Fertility and the environment in a natural resource dependent economy: Evidence from Petén, Guatemala. Población y Salud enMesoamérica, 2(1): 1-14.

Tuirán, R. (1993). Vivir en familia: hogares y estructura familiar en México 1976-1987, Comercio Exterior. Vol.43, No.7, Mexico, July.

Wilson, E.O. (2002). The future of life. New York: Alfred A. Knopf.

World Resources Institute. (1998). World resources 1998-99. A guide to the global environment: Environmental change and human health. New York: Oxford University Press. 